\title{
LOGICO SEMANTIC RELATION ANALYSIS OF CLAUSE COMPLEX IN CNN NEWS
}

\author{
Niken Sri Noviandari; Dolar Yuwono \\ Institut Agama Islam Negeri (IAIN) Ponorogo
}

\begin{abstract}
This study deals with Logico Semantic Relation in CNN News text. The objectives of this study is to discover the types of Logico Semantic Relation of Clause Complex Used in CNN News and to know the dominant type of logical semantic systems interpreted in CNN News. The researcher applied qualitative approach and used content analysis design. The technique of collecting data was documentation. The data of the research was Logico Semantic Relation meanwhile the news text of CNN was as the data source of the research. The data were analyzed by data reduction, data display, and conclusion drawing/verification. The findings showed that (1) The types of Logico Semantic Relation used in the five news texts of CNN were Expansion (Elaboration, Enhancement, and Extension) and Projection (Locution). The total number of Logico Semantic Relation was 201 or $100 \%$ which consisted of 153 items or $76,10 \%$ of expansion and 48 items or $23,90 \%$ of projection. (2) Expansion (Elaboration) was the most dominant type among all kinds of Logico Semantic Relation which appeared in 92 times or 45,80\%. The second rank was projection (locution) that was 48 times or $23,90 \%$. The third position was expansion (Enhancement) which occurred 33 times or 16,40\%. Meanwhile, Expansion (Extension) appeared 28 times or 13,90\%, and the last one was projection (idea), which had no percentage ( 0 times or $0.00 \%)$. The researcher concludes that there are two types of Logico Semantic Relation used in the CNN news text, those are Expansion (Elaboration, Enhancement, and Extension) and Projection (Locution). The most dominant type of Logico Semantic Relation that appears in the text is Expansion (Elaboration).
\end{abstract}

Keywords: CNN News, Clause complex, logico-semantic relation.

\section{INTRODUCTION}

In this millennium era, learning English has a very significant role. English is the language that is used to communicate in the whole world. By being able to speak English well, somebody can be easily to express their message to the people from the other countries or to catch the message from the foreigner whether oral or written. It helps everyone who comes from different language and countries to interact easily. However, if people do not have ability to speak English well, they will have some difficulties to interact with foreigner. Moreover, mastering English is a must for the students who study in a university which contributes to their professional career in the future, because nowadays almost all new technology uses English as the language. Besides, most of universities in Indonesia have applied English test to select and to increase the quality of the 
students. Especially for students who want to continue their study abroad or whoever who want to get a good job, the must have a certificate of English test such as TOEIC, TEFL, IELT with a certain score. All of these cannot be reached easily without a good ability of English. So, the importance of mastering English in this millennium era cannot be avoided.

English consists of four language skills, those are writing, reading, speaking, and listening which are mastered by students. In Indonesia, English language teaching concerns with text or genre. Consequently, it is important to apply SFL (Systemic Functional Linguistic) in writing a text or constructing a sentence. It is as important as applying grammar or structure. Meanwhile, SFL plays an important role in English language teaching.

To understand the meaning of a text, we can analyze it by its sentence. Sentence must consist of some units, such as words, phrase, and clause. In composing a good sentence, people cannot be only focused on the grammar or the structure but also to the meaning. Besides, to make a meaningful sentence, people also must concern how the structure construct the meaning and also the structure of each clause because to know whether a sentence is good nor not we can see from the structure of each clause.

There are two kinds of clause that important to be understood. Those are clause simplex and clause complex. Clause complex is the term systematists used for the grammatical and semantic unit formed when two or more clauses are linked together in certain systematic and meaningful ways, while clause simplex refers to single clause units (or sentence of only one clause) (Suzzane Eggins, 2004). A clause complex is composed of one clause after another clause after another clause. In other words, a sentence can be called as a clause complex when the sentence consists of some clause which have good structure and meaning. Each clause must have relation with the other clause. Therefore, if there is a sentence that consists of some clauses but there is no relation among the clauses, it cannot be called as a clause comlpex. Regarding to clause complex and its relation to meaning, Halliday (1985:193) stated that we shall consider the connections between the clauses as the logical component of the linguistic system: the functional semantic relationships which constitute the logic of natural language. It concludes that a clause complex should have a cohesive unit in which there is a logical relation regarding to a semantic view mentioned as logical semantic relation. The categories of clause complex relation actually apply over other areas of the grammar as whole: not just clauses but also groups and phrases form 'complex' and they do so along the same principles as the clause. Thus, the writer chooses to analyze clause complex over clause simplex.

Therefore, in understanding the meaning of a sentence the students need to have ability about logico semantic analysis system. Logico-semantic system is the system that defines the particular form of relationship of meaning between related clauses (Suzzane Eggins, 2004). It studies about the incorporation either 
dependent or independent clause. There are two main options clauses may be related through projection or expansion. Therefore, logico semantic is important to be understood by the students.Whereas, logico semanticis the subject which needs more concentration and more focus to undersand. It is very important to analys the meaning of clause especially in a claus colmplex. Thus, based on the background above the researcher is encouraged to conduct a research dealing with Logico Semantic Relation Anylis of Clause Complex Based on SFL in CNN News.

\section{METHODS}

In this study, the researcher conducted a qualitative research method. Khotari (1990) mentioned that qualitative research is a research that concerns qualitative phenomena. Donald Ary (2010) stated that qualitative researchers seek to understand a phenomenon rather than breaking it down into variables by focusing on the overall picture. In other words, qualitative research is research that focuses on analyzing the data in form of words rather than numerical data. While the research design, the researcher applies a content or document analysis as the research design. Content or document analysis is a form of analysis applied to written or visual materials to classify defined material characteristics. The analyzed resources may be journals, magazines, web sites, interviews, tv programmers, commercials, musical works, or any of a variety of other types of records (Donald et al., 2010).

In this research, data source that the researcher used are the students of English Department who are taught Systemic Functional Linguistic and the text of CNN news. Interview and documentation are used to obtain the data about the student's perspective about Systemic Functional Linguistic subject and to obtain the data about logico semantic relation.

As a consequence, the data collected should be analyzed and reported by the researcher as the result. The researcher arrives to do the study after gathering the data to find out the research questions in this study. Qualitative data analysis is a process in which data are checked and organized, and extracted from observation, interview and recording. Qualitative data analysis consists of three current activity flows: data reduction, display, and verification of the data. Qualitative research can make their research findings more credible by drawing from evidence from a variety of data sources. After that, a triangulation technique is used to validate the data. Triangulation was suggested as a means to improve validation levels or to strengthen the legitimacy of research studies by contrasting the outcomes of various methods with a common unit of analysis.

\section{FINDINGS}

\section{Types of Logico Semantic Relation}

The findings of this research present the data from documentation. Data 
analysis in this part describes logico-semantic relation system used in CNN News Texts that consist of projection (locution and idea) and expansion (extension, elaboration, and enhancement).

a. Types of Logico Semantic Relation Used in Texts 1

Based on the text entitled "Skipping Breakfast Tied to Higher Risk of Heart-Related Death, Study Finds.", it was found that there are 35 sentences in text 1 , which 27 of them are clause complex. It also found that the text contains some types of logico semantic relation, those are Projection (Locution) and Expansion (Extension, Elaboration, and Enhancement). There are 12 items of locution, 7 Extension, 27 Elaboration, and 5 Enhancement, with total number is 52 logico-semantic relation. The most dominant of text 1 is Expansion (Elaboration).

\section{b. Types of Logico Semantic Relation Used in Texts 2}

The title of the text 2 is "Girl's Deadly Reaction to Toothpaste Is Extremely Rare, Allergist Reminds Parents.". It was found that there are 17 sentences in text 2 ("which 14 of them are clause complex. It also found that the text contains some types of logico semantic relation, those are Projection (Locution) and Expansion (Extension, Elaboration, and Enhancement). There are 9 items of locution, 6 Extension 10 Elaboration, and 4 Enhancement, with total number is 29 logicosemantic relation. The most dominant of text 2 is Expansion (Elaboration).

\section{c. Types of Logico Semantic Relation Used in Texts 3}

There are 34 sentences in text 3 "Stop Letting Your Kids Stare at iPads in Restaurants, Science Says."), which 19 of them are clause complex. It also found that the text contains some types of logico semantic relation, those are Projection (Locution) and Expansion (Extension, Elaboration, and Enhancement). There are 1 items of locution, 4 Extension 16 Elaboration, and 9 Enhancement, with total number is 30 logico-semantic relation. The most dominant of text 3 is Expansion (Elaboration).

\section{d. Types of Logico Semantic Relation Used in Texts 4}

There are 22 sentences in text 4 ("Climate Changes is Helping Spread a Fungus that Attacks Bananas"), which 13 of them are clause complex. It also found that the text contains some types of logico semantic relation, those are Projection (Locution) and Expansion (Extension, Elaboration, and Enhancement). There are 5 items of locution, 4 Extension 6 Elaboration, and 5 Enhancement, with total number is 30 logico-semantic relation. The most dominant of text 4 is Expansion 
(Elaboration).

\section{e. Types of Logico Semantic Relation Used in Texts 5}

There are 51 sentences in text 5 "Sunscreen Enters Bloodstream after Just One Day of Use, Study Says"), which 38 of them are clause complex. It also found that the text contains some types of logico semantic relation, those are Projection (Locution) and Expansion (Extension, Elaboration, and Enhancement). There are 20 items of locution, 7 Extension 33 Elaboration, and 10 Enhancement, with total number is 30 logico-semantic relation. The most dominant of text 5 is Expansion (Elaboration).

\section{The dominant Types of Logico Semantic Relation Used in CNN News}

There are 201 logico-sematic relations or $100.00 \%$ of total number or logico-semantic relations, which consisted of 153 items or $76,10 \%$ of expansion and 48 items or $23,90 \%$ of projection. From the table above, Expansion (Elaboration) is the most frequent type among all the types of logico-semantic relations which appears 92 times or $45,80 \%$. it based on this calculation $\frac{92}{201} \times 100 \%$. It means that Elaboration is the dominant type of Logico Semantic Relation used in the text. The second rank is projection (locution) that is 48 times or $23,90 \%$, it based on this calculation $\frac{48}{201} \times 100 \%$. The third position is expansion (Enhancement) which occurs 33 times or $16,40 \%$, it based on this calculation $\frac{33}{201} \times 100 \%$. Meanwhile, Expansion (Extension) appears 28 times or 13,90\%, it based on this calculation $\frac{28}{201} \times 100 \%$. And the last one is projection (idea), which has no percentage ( 0 times or $0.00 \%)$.

\section{DISCUSSION}

There are 92 items or 45,80 \% of elaboration used in the 5 CNN News texts. Elaboration is used the most in the text. Elaboration is shown through the equal $(=)$ symbol. While the symbol alpha $(\alpha)$ and beta $(\beta)$ indicates the independent and dependent clauses. Alpha $(\alpha)$ indicates the independent clause and beta $(\beta)$ indicates the dependent clause. The following are examples of elaboration which are taken from text 3 and text 5 :

$\alpha \quad$ There are no studies

that warns against having too many hours of those activities.

(Text : 3, Sentence: 33)

(2) $\quad \alpha \quad$ The new FDA study enrolled 24 healthy volunteers who were randomly assigned to a spray or lotion screen

(Text : 5, Sentence: 19) 
$\alpha \quad$ oxybenzone remains in use;

$\beta \quad$ in fact, a 2018 report by the new EWG estimated that it was two-third of chemically based sunscreens sold in the United States.

(Text : 5, Sentence: 33)

The word that in the second clause is identified as expansion (elaboration). And 'in fact' on the third sentence also act as the indication of elaboration. The words are indicated for specifying in greater detail of clause complex.

There are 28 items or 13,90\% of extension used in the CNN News text. Extension is marked by the plus (+) symbol. While the number 1,2,3 and so on, indicates the initiating and continuing clauses. The symbol of number 1 indicates the initiating clause and number 2,3, and so on indicates the continuing clauses. The following are examples of extension which are taken from text 1 and text 5:

Breakfast is traditionally believed as the most or at least one of the most important meals of the day,

But there are not much data available to say 'yes' or 'no' to this belief.

(Text : 1, Sentence:4)

) More research is needed to determine whether missing the meal actually

And why such an association exists.

(Text : 1 , Sentence : 21)

) Oxybenzone was absorbed into the body at about 50 to 100 times

higher concentration

Than any of these other three chemical they tested.

The word but in the first example above is identified as expansion (extension) and the word and, and than in the second and third examples are also identified as expansion (extension). Those words indicate for giving an exception and adding some new element in a clause complex.

There are 33 items or 16,40 \% of extension used in the CNN News text. Enhancement is shown through the ( $\mathrm{x}$ ) symbol. While the number 1,2,3 and so on, indicates the initiating and continuing clauses. The symbol of number 1 indicates the initiating clause and number 2,3, and so on indicates the continuing clauses. The following are examples of extension which are taken from text 1, 2, and 5:

) Or B. if you need to do 16 hours, 
Try to consider skipping dinner and not breakfast or lunch.

(Text : 1,Sentencez: 35)

) We don't want to trivialize this,

Because we want people to be careful.

(Text : 2,Sentencez: 15)

) While science continues to answer question about sunscreen, Callif and other experts call for the public to continue to protect their skin from the dangerous rays of the sun.

(Text : 5,Sentencez: 46)

The word if in the first example above is identified as expansion (enhancement), the word because in the second example is also identified as expansion (enhancement) and the word while in the third example is also identified as enhancement. Those words are indicated for qualifying circumstantial of condition in a clause complex.

There is 48 item or $23,90 \%$ of logico-semantic relations of locution which were used in the CNN News texts. Locution which is mostly used in the texts is parataxis. It has function to present a construction of wording. The following are the examples of locution which taken from text 1 and 4:

) Our paper is among the ones that provide evidence to support long-term benefits,

Bao said.

(Text : 1,Sentencez: 5)

) Longo warns

Be careful

(Text : 1,Sentencez: 32)

) $\boldsymbol{\alpha}$ New research suggest

$\boldsymbol{\beta}$ That climate change is aiding the spread of this highly destructive plant infection.

(Text : 4,Sentencez: 2)

The verbal words such as 'said', 'warns', 'suggests', indicate the projection of locution. There is $0 \%$ idea used in the CNN News text. It means, idea is the least used in the text.

\section{CONCLUSION}

The types of logico semantic relation that is used in the five news texts of CNN are Expansion (Elaboration, Enhancement, and Extension) and Projection (Locution). The total number of logico semantic relation is 201 or $100 \%$ in which in which 153 items or $76,10 \%$ of expansion and 48 items or $23,90 \%$ of projection. 
The most dominant type of logico semantic relation is Expansion (Elaboration), which appears in 92 times or $45,80 \%$. The second rank is projection (locution) that is 48 times or $23,90 \%$. The third position is expansion (Enhancement) which occurs 33 times or 16,40\%. Meanwhile, Expansion (Extension) appears 28 times or 13,90\%, and the last one is projection (idea), which has no percentage ( 0 times or $0.00 \%$ )

\section{REFERENCES}

DeFord , Christine, (2008). CNN.com Analysis.

Donald, A. (2006). Introduction to Research in Education. USA: Wadsworth.

Eggins, S. (2004). An Introduction to Systemic Functional Linguistics, (New York : NY 0010.

Gerot, L. \& Wignell, P. (2000). Making Sense of Functional Grammar. Australia: AEE Publishing.

Given, Lisa. M. (2008). The Stage Encyclopedia of QUALITATIVE RESEARCH METHODS: volume 1\&2. Thousand oaks: SAGE.

https://edition.cnn.com/2019/04/17/health/meals-ipads-screens-familydinner pare nting-go-ask-your-dad/index.html, accessed from internet on April 28 ${ }^{\text {th }}, 2019$.

https://edition.cnn.com/2019/04/22/health/skipping-breakfastcardiovascular death -study/index.html, accessed from internet on April 28th 2019.

https://edition.cnn.com/2019/04/22/health/toothpaste-deadly-allergicreaction per spective/index.html, accessed from internet on April 28 ${ }^{\text {th }}$, 2019.

https://edition.cnn.com/2019/05/07/health/banana-disease-climatechangetrnd/in dex. html, accessed from internet on May 12 2019.

https://edition.cnn.com/2019/05/06/health/sunscreen-bloodstreamfdastudy/index. html, accessed from internet on May 12 ${ }^{\text {th }}, 2019$.

Khotari, C.R. (2014). Research Methodology, India: New Age.

Mathew B. Miles, Mathew B., \& Huberman, M. (1994). An Expanded Sourcebook Qualitative Data Analysis. California: SAGE.

Widiastuti, E. (2013). An Analysis Oo Logico-Semantic Relation of Clause Complexes In Breaking News of VOA. Universitas Muria Kudus..

Yuwono, D. (2016). Writing from Practice to Theory: Getting Smart and Creative to Write. Yogyakarta: Magnum Pustaka Utama. 